\title{
NEW ALTERNATIVE CORONARY BYPASS GRAFT: FIRST CLINICAL EXPERIENCE WITH AN AUTOLOGOUS ENDOTHELIALIZED CRYOPRESERVED ALLOGRAFT
}

\author{
Peter Lamm, MD, ${ }^{\mathrm{a}}$ Gerd Juchem, MD, ${ }_{\mathrm{b}}$ Peter Weyrich, ${ }^{\mathrm{c}}$ Stephan Nees, MD,${ }^{\mathrm{c}}$ and Bruno Reichart, MD, ${ }^{\mathrm{a}}$ Munich, Germany
}

A 72-year-old woman with unstable angina and dyspnea came to our department in October 1997 for evaluation of the possibility of an aorta-coronary bypass operation. Coronary angiography showed severe 3 -vessel disease combined with significant left main coronary artery stenosis. In the ventriculogram the posterior wall of both ventricles was seen to be akinetic as the result of a previous myocardial infarction. There was evidence of a significant mitral insufficiency. The ejection fraction was 0.45 . Cardiopulmonary resuscitation was needed several times, the most recent occasion being in November 1997. In addition the patient had hypertension and insulin-dependent diabetes mellitus, resulting in diabetic kidney failure and peripheral polyneuropathy. The patient had previously had 2 strokes, leading to the paraparesis of both legs, and as a result required a wheelchair. Femoral-popliteal reconstructions were done on both legs, with early graft thrombosis. In addition this patient was a known carrier of factor $\mathrm{V}$ Leiden mutation.

Initially the lack of sufficient bypass material prevented an operation. The veins of both legs had been used previously for peripheral revascularization. Because of the possibility of

From the Departments of Cardiac Surgery a and Anesthesiology, ${ }^{\mathrm{b}}$ Klinikum Großhadern, and the Department of Physiology, ${ }^{c}$ Ludwig-Maximilians-Universität München, Munich, Germany.

Received for publication Dec 4, 1998; accepted for publication Jan 20, 1999.

Address for reprints: Peter Lamm, MD, Herzklinik der Universität München am Augustinum, Wolkerweg 16, 81375 Munich, Germany.

J Thorac Cardiovasc Surg 1999;117:1217-9

Copyright (C 1999 by Mosby, Inc.

$0022-5223 / 99 \$ 8.00+0 \quad \mathbf{1 2 / 5 4 / 9 7 3 8 0}$ infection and instability of the sternum, the combined use of left and right internal thoracic arteries was regarded as being too risky. The use of a wheelchair prevented the use of the radial arteries. Because of the resistant and intractable angina, we decided to perform the revascularization with an autologous endothelialized cryopreserved vein allograft. It was possible to harvest a 4-cm long vein remnant from the right leg and isolate human saphenous vein endothelial cells. Cultivation was done by regular cell tissue techniques. Once a sufficient number of human saphenous vein endothelial cells (approximately $5 \times 10^{6}$ cells) was available, an ABOcompatible cryopreserved vein allograft was thawed rapidly in water at $37^{\circ} \mathrm{C}$. For the total removal of the native human saphenous vein endothelial cells, a Fogarty catheter was rigorously pulled through the vein in the direction of the original blood flow to prevent damage to the venous valves. The vein was then filled with the patient's autologous serum and placed in an incubator at $37^{\circ} \mathrm{C}$ for approximately 12 hours. Subsequently vein endothelialization was initiated by seeding $1.2 \times 10^{5}$ human saphenous vein endothelial cells $/ \mathrm{cm}^{2}$ inner graft surface in a rotating device ( 3 hours, $37^{\circ} \mathrm{C}, .25 \mathrm{rpm}$ ). After homogeneous adhesion of the human saphenous vein endothelial cells to the inner graft surface had been achieved, the vein was placed in a special cultivation apparatus (Fig 1). After 7 days of cultivation the implantation of this graft on the circumflex artery was performed on January 14, 1998, with the written informed consent of the patient. The left anterior descending artery was bypassed with the left internal thoracic artery. The operation took place without complications. Intraoperative flow measurements of the vein allograft documented a flow of $90 \mathrm{~mL} / \mathrm{min}$. Scanning electron microscopic evaluation of preoperatively and intraoperatively collected samples of the vein wall showed an intact endothelium 


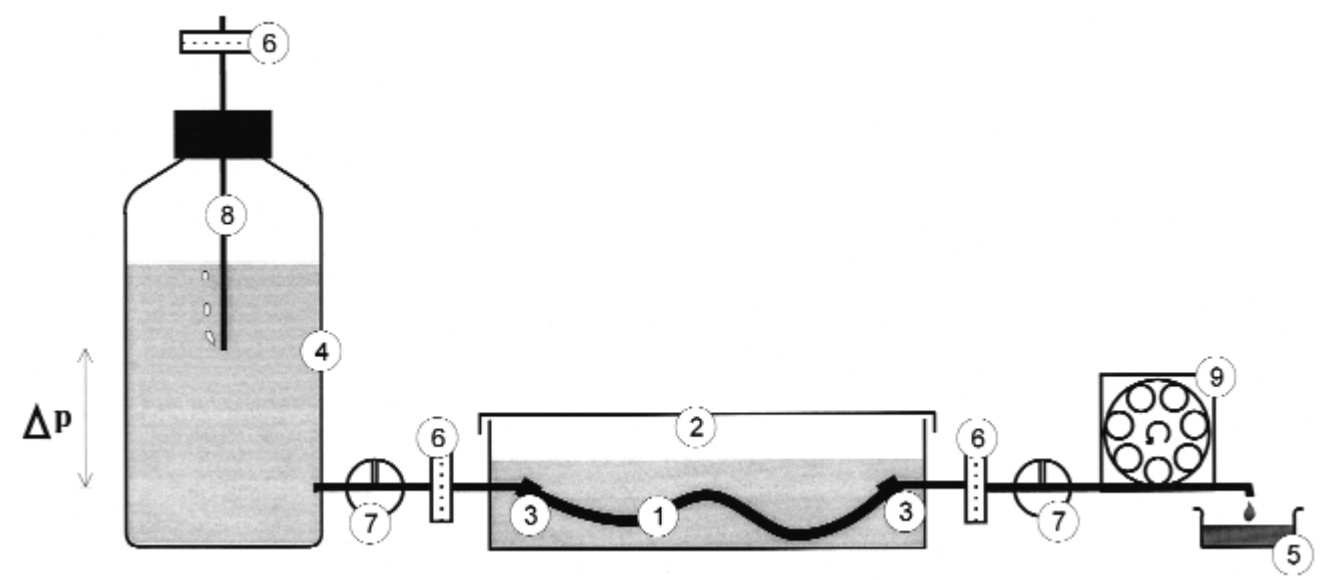

Fig 1. Endothelialization of venous allograft. Vein (1), in which autologous endothelial cells have already been seeded, is maintained in medium-filled cultivation vessel (2). Ends of vein are attached to vessel outlets with adapters (3). Distal vessel end is attached to medium-filled Boyle-Marriot bottle (4). Proximal end leads to wastecollection vessel (5). Both ends include sterile filters (6) and 3-way taps (7). Pressure gradient $(\Delta P)$, which depends on depth of cannula (8), is chosen to just prevent collapse of vein. Medium in vein lumen is exchanged daily by computer-controlled pump (9).

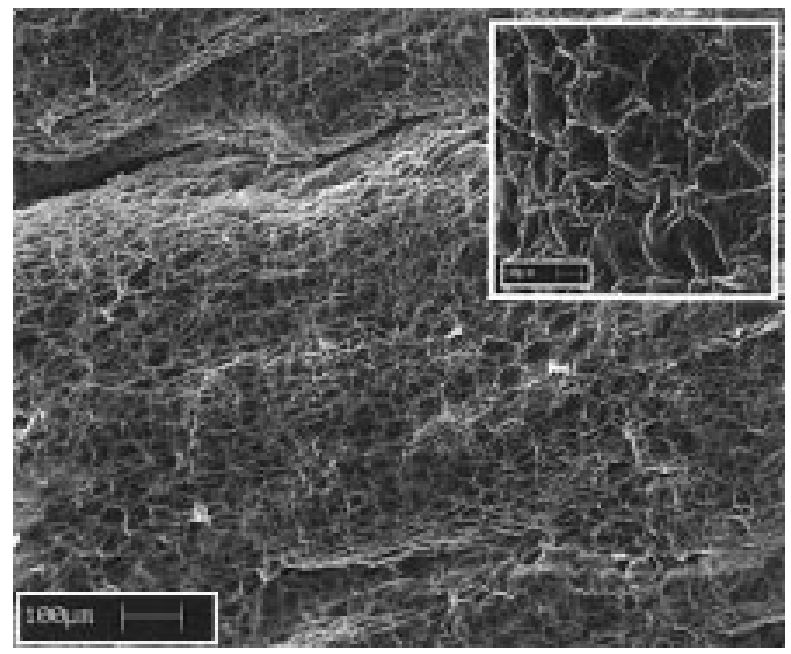

Fig 2. Scanning electron micrograph of interior surface of vein after successful continuous re-endothelialization of entire inner surface with autologous saphenous vein endothelial cells (sample taken immediately before central anastomosis of vein graft). (Original magnification 30×.). Inset is at higher magnification. (Original magnification 100×.)

(Fig 2). Thirteen hours after the operation the patient was extubated and 4 days later she was referred to the regular ward. Postoperative hemodynamics and ultrasonographic cardiography demonstrated increased myocardial function. On examination 181 days later, the bypass was determined angiographically to be open and nondilated (Fig 3). Since the operation the patient has not had recurrence of angina. Immunosuppressive agents were not administered.

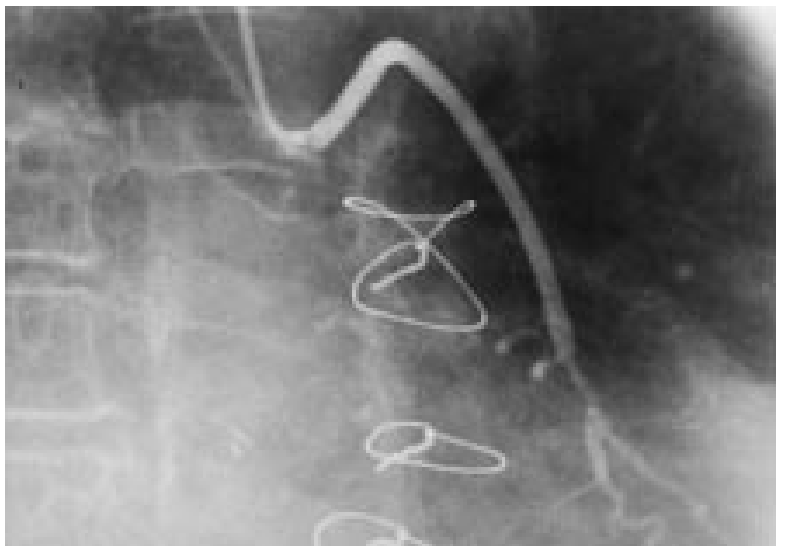

Fig 3. Coronary arteriogram of autologous endothelialized venous coronary artery bypass 181 days after operation. Arteriogram shows patent, nondilated allograft.

Discussion. Cryopreserved vein allografts have been used in treatment of patients without sufficient autologous graft material. ${ }^{1-4}$ The lack of vascular endothelium has generally been considered to be responsible for early graft failure. ${ }^{1,4}$ Autologous endothelialization ${ }^{5}$ of cryopreserved vein allograft may be the long sought answer, providing a new and reliable source of bypass material with long-term patency. In a current research project at our clinic we developed a simple, reliable, and reproducible method of endothelializing cryopreserved vein allografts with the patient's autologous endothelial cells. The production period of these endothelialized grafts is about 3 weeks. Histologic studies of these grafts after perfusion have shown a stable and intact endothelium that cannot be distinguished from regular endothelium. 
The case presented here demonstrates that the use of autologous endothelialized cryopreserved allograft veins may make bypass procedures available even to those patients whose disease to date has been considered inoperable because of a lack of bypass material. The easy handling of such veins and the simplicity of the coating procedure should be a considerable step forward in cardiovascular surgery. We are currently selecting new candidates with apparently inoperable disease for further clinical application of this new technique.

\section{REFERENCES}

1. Brockbank KG, McNally RT, Walsh KA. Cryopreserved vein transplantation. J Cardiac Surg 1992;7:170-6.
2. Gelbfish J, Jacobowitz IJ, Rose DM, Connolly MW, Acinapura AJ, Zisbrod Z, et al. Cryopreserved homologous saphenous vein: early and late patency in coronary artery bypass surgical procedures. Ann Thorac Surg 1986;42:70-3.

3. Fujitani RM, Bassiouny HS, Gewertz BL, et al. Cryopreserved saphenous vein allogenic homografts: an alternative conduit in lower extremity arterial reconstruction in infected fields. J Vasc Surg 1992;15:519-26.

4. Brockbank KG, Donovan TJ, Ruby ST, et al. Functional analysis of cryopreserved veins. J Vasc Surg 1990;11:94-102.

5. Herring MB, Gardner AL, Glover J. A single-staged technique for seeding vascular grafts with autogenous endothelium. Surgery 1978;84:498-504. 